\title{
Effects of presence and absence of information about shock intensity upon licking suppression in rats $^{1}$
}

\author{
MASAYA FUJII. MASAKO UCHIDA and HIROSHI IMADA \\ Department of Psychology, Kwansei Gakuin University, Uegahara, Nishinomiva, Hyogo 662
}

Two groups of rats were run to examine the effects of presence and absence of information about shock intensity upon the suppression of rats' licking behavior. Shocks of two different intensities were consistently preceded by signals of two different modalities. The modality of signal and the shock intensity were comelated for Group C (Correlated), but they were not for Group UC (Uncorrelated). Group C clearly evidenced shock intensity discrimination which was maniw fested in differential conditioned suppression. The baseline licking behavior of rats was suppressed more in Group UC than in Group C, indicating that there was more aversion to the situation in which information about shock intensity was not given than to the situation in which such information was given. The findings were discussed with reference to the results of a computer simulation based on the Rescorla-Wagner model (Rescorla \& Wagner, 1972).

Key words: information about shock intensity, uncertainty. contextual fear. Rescorla-Wagner model. computer simulation, licking suppression, rats.

It has been shown that animals placed in a signaled-shock situation prefer the condition which provides precise information about the nature of the shock (D'Amato \& Safarjan, 1979; Marlin. Sullivan, Berk, \& Miller, 1979). For example, D'Amato and Safarjan (1979) found, in a change-over bar-pressing situation, that rats preferred the condition in which two different signals were correlated with two different shock durations to the condition in which the signals and durations of shocks were uncorrelated. Marlin et al.

'The present research was supported by a Grantin-Aid for Scientific Researches (No.57510060), Ministry of Education of Japan, to Hiroshi Imada. We would like to express our gratitude to Ryouji Nakagawa for his help in running the experiment. We would like to express our appreciation to Andrea H. Rupert for editing an earlier draft of this paper.

2 Correspondence conceming this article should be addressed to Masaya Fujii, who is now at Graduate School of Psychology, Fuller Theological Seminary, 180 N. Oakland Avenue, Pasadena, CA 91182 , U.S.A., or to Hiroshi Imada, Department of Psychology, Kwansei Gakuin University, Uegahara, Nishinomiya, 662 Japan.
(1979) reported that, given a two-compartment choice situation, rats showed preference for the compartment in which two different signals were correlated with two different shock intensities to the compartment in which the signals and intensities of shocks were uncorrelated. These findings suggest that information about the nature of impending shocks, such as their duration or intensity, plays an important role in determining rats' choice behavior. However, the test situations designed by the above researchers do "not give firsthand information about moment-to-moment changes in the rat's emotional state, which the suppression technique can provide" (Imada \& Nageishi, 1982, p. 586).

The present experiment was designed to examine the effects of information about shock intensity upon rats' behavior in a licking suppression situation. The advantage of using an on-baseline conditioned suppression situation for such a purpose is that it enables continuous measurement of a rat's emotional state as reflected by varying licking suppression over time. It therefore provides more 
information in order to identify specific determining factors of rats' preference for the correlated condition over the uncorrelated condition. In other words, it becomes possible to identify whether it is a difference of fear evoked by conditioned stimulus (CSfear) or contextual fear or both that brings about the preference. This, in turn, makes it possible to analyze the data with reference to Fanselow's contextual fear hypothesis (Fanselow, 1980) which is based on the Rescorla-Wagner model of classical conditioning (Rescorla, 1972; Rescorla \& Wagner, 1972; Wagner \& Rescorla, 1972).

To restate the purpose of the present experiment more specifically, the purpose was to study the effects of presence and absence of information about shock intensity on the suppression of licking behavior in rats both during the signal and in its absence (context). The adequacy of the contextual fear hypothesis for explaining the results were tested by comparing the actual data with the results of a computer simulation based on the Rescolra-Wagner model.

\section{Method}

\section{Subjects}

The subjects were 28 experimentally naive male Wistar rats purchased from Keari Co., Ltd. (Osaka, Japan). The body weight of the subjects at the beginning of the experiment varied from 215 to $289 \mathrm{~g}$ (mean: $256 \mathrm{~g}$ ).

\section{Apparatus}

The apparatus consisted of four identical drinking boxes which had been used in the present writers' previous research (e.g., Nageishi \& Imada, 1974; Imada, Shuku, \& Moriya, 1983). Each drinking box contained a $20 \times 10 \mathrm{~cm}$ grid floor and was $15 \mathrm{~cm}$ high. In the lower part of the wall at one narrow end of the box was a hole $(12 \mathrm{~mm}$ in diameter) through which the rat could gain access to a drinking tube. When a rat made contact with the drinking tube, a MOS-FET-based electronic circuit was completed, which activated a reed relay located in an adjacent room. These four boxes, each having a transparent ceiling and white walls, were placed on a table in such a way that each of the boxes was equidistant from two adjacent boxes. The drinking-hole-wall of each box faced outward from the center of the table. A fan was attached directly below the center of the table to provide a masking noise of approximately $64 \mathrm{~dB}$ ("C" setting). The entire apparatus was illuminated during the experiment by indirect lighting, which shed light of approximately $5.2 \mathrm{~lx}$ into each box. An audible tone and additional light were used as the two conditioned stimuli (CSs) in the present experiment. The auditory CS (tone) was a $1000 \mathrm{~Hz}$ pure tone, approximately $84 \mathrm{~dB}$ ("C" setting), delivered from a speaker suspended $200 \mathrm{~cm}$ directly above the center of the table. The visual CS (light) was provided by turning on an electric lamp suspended $173 \mathrm{~cm}$ directly above the center of the table, which increased the illumination inside each box to approximately $113 \mathrm{~lx}$. The duration of each CS was $5 \mathrm{~s}$. The electric shock of 0.7-s duration was delivered via an alternating current shock source to the grid floor through a $250-\mathrm{k} \Omega$ current-limiting resistor put in series with the rats.

\section{Procedure}

Prior to the start of the experiment, the subjects were tamed by handling for $5 \mathrm{~min}$ per day for 5 consecutive days. Beginning with the third day of handling, all rats were placed on a 25-min-per-day watering schedule that was maintained throughout the experiment. This watering schedule took place in their home cages. The experiment consisted of three phases.

Phase 1: Preliminary training of drinking (22 days). All the subjects were trained 5 min daily to drink tap water by licking the tip 
of the drinking tube in the drinking boxes. After the daily training, the rats were returned to their respective home cages and allowed to drink water there for another 25 min. This preliminary training of drinking was continued for 22 days, until the total amount of water drunk in 5 min stabilized for all the rats. The mean total number of licks for the last + days was 1500.5 (approximately 5.0 licks per second).

Phase 2: Conditioning (18 days). The subjects were then divided into two groups of 14 subjects each, matched on the basis of the mean number of licks and body weight on Days 19 and 20 of the preliminary training phase. The two groups were labeled as Groups C (Correlated) and UC (Uncorrelated), respectively. On each day of Phase 2, each subject received four conditioning trials. A trial consisted of a paired presentation of a CS and a shock; all shocks were signaled. The two groups differed with respect to the information that the signals carried concerning the intensity of the impending shock (see Figure 1). In Group C. the CS modality and the shock intensity were correlated: One of the two kinds of $\mathrm{CS}\left(\mathrm{CS}_{\mathrm{A}}\right)$ was always followed by the weak shock $\left(\mathrm{ES}_{\mathrm{w}}\right)$; the other CS $\left(\mathrm{CS}_{B}\right)$ was followed by the strong shock $\left(E S_{s}\right)$. The subjects in Group UC received uncorrelated presentations of the CS and the shock: The $\mathrm{CS}_{\mathrm{A}}$ (or $C S_{B}$ ) was followed by the weak shock on one trial and by the strong shock on the other trial. Six types of stimulus sequences were used for both groups. Note that: (a) Both $C S_{A}$ and $C S_{1 s}$ were presented at the same temporal locations in the two groups. (b) To examine the effects of each CS upon licking across groups without being confounded by modality differences, target trials were arranged (i.e., on two of the four trials in each session, the CS modality, the US intensity, and the trial location were matched across groups; see Trials 3 and 4 of Figure 1). (c) The $\mathrm{CS}_{\mathrm{A}}$ (or $\mathrm{CS}_{\mathrm{B}}$ ) was a tone for half of the subjects and was a light for the other half in both groups. (d) The mean intertrial interval was $73.8 \mathrm{~s}(15-125 \mathrm{~s})$.

The intensity of the strong shock was $140 \mathrm{~V}$ for the first 8 days and was increased to $180 \mathrm{~V}$ for the remaining 10 days. The weak shock was kept at $90 \mathrm{~V}$ throughout the conditioning phase. The estimated values of current flow, assuming the rats' resistance to be $100 \mathrm{k} \Omega$, were $0.3 \mathrm{~mA}(90 \mathrm{~V}), 0.5 \mathrm{~mA}$ $(140 \mathrm{~V})$, and $.6 \mathrm{~mA}(180 \mathrm{~V})$.

Phase 3: Extinction ( 9 davs). The same CS sequences as those used in Phase 2 were used for all subjects. No shocks were given during this phase.

\section{Results}

\section{Baseline Suppression}

The upper panel of Figure 2 shows the

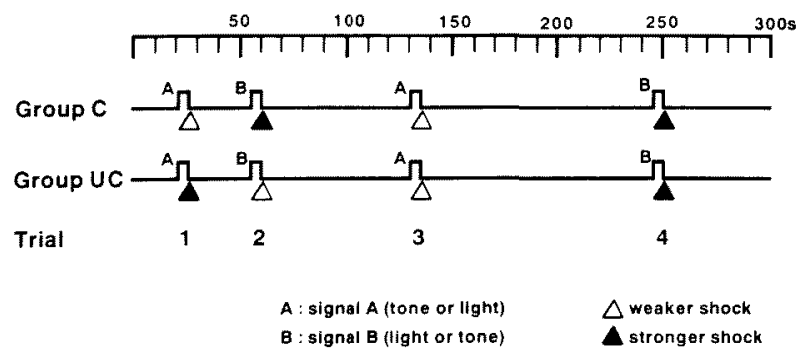

Figure 1. An example of stimulus sequences used in the experiment. 
mean baseline number of licks per $5 \mathrm{~s}$ as a function of conditioning and extinction days. The baseline number of licks for a rat in a session was calculated by subtracting the number of licks during the presentation of CSs from the total number of licks for that session. As shown in the left one-third of the upper panel, there is no marked difference between the licking pattern of Groups $\mathrm{C}$ and UC during the initial eight days of conditioning. Each group gradually increased baseline licking over this period. However, when the intensity of the stronger shock was increased from $140 \mathrm{~V}$ to $180 \mathrm{~V}$, the curves for the two groups diverged as a function of conditioning days. A Groups (2) $\times$ Days (10) ANOVA conducted for the mean baseline number of

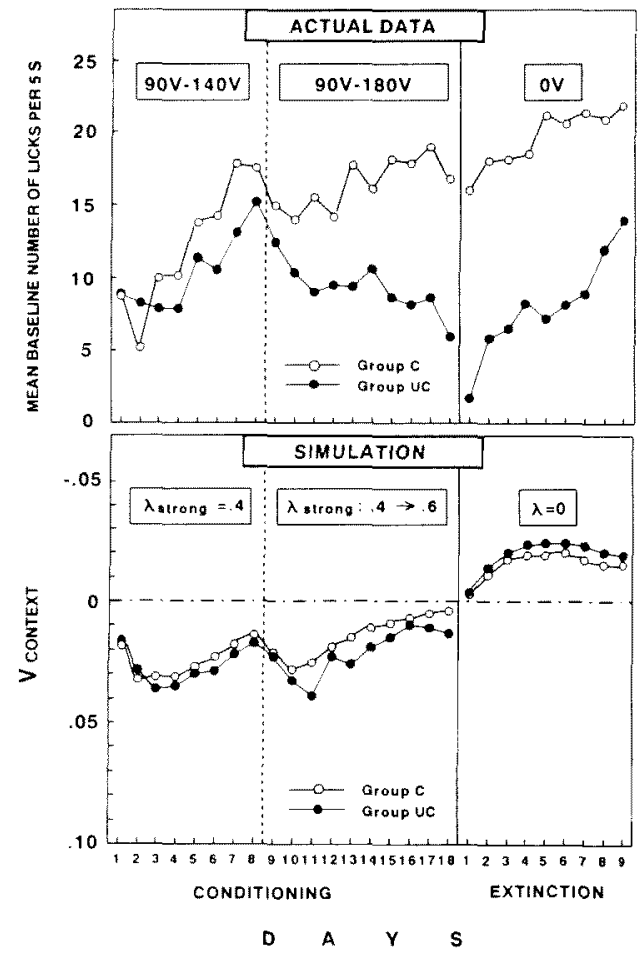

Figure 2. Means of baseline number of licks per $5 \mathrm{~s}$ during both conditioning and extinction (upper panel) and corresponding simulation results for the associative strength of the context, $V_{\text {cowrexf }}$ (lower panel). For details of simulation, see text and appendix. licks for Days 9 through 18 revealed that the main effect of Groups and the Groups $\times$ Days interaction effect were significant $(F(1,26)=7.60, p<.05 ; F(9,234)=3.11, p<.01$, respectively). The main effect of Days was not significant $(F<1)$.

The resultant difference between these two groups was also confirmed by statistical analysis of the extinction phase. This outcome is depicted in the right one-third of the upper panel of Figure 2. A Groups (2) $\times$ Days (9) ANOVA revealed that the main effect of Groups, the Groups $\times$ Days interaction effect, as well as the main effect of Days were significant $(F(1,26)=24.77, p<.001$; $F(8,208)=2.42, p<.05 ; F(8,208)=14.06$, $p<.01$, respectively). These results clearly indicate that Group UC showed greater baseline suppression than did Group C.

The lower panel of Figure 2 summarizes the results of a computer simulation of the associative strength of contextual stimuli $\left(\mathrm{V}_{\text {CONTEXY }}\right)$. It served to generate a hypothetical outcome of this experiment. A detailed description of this simulation will be given below.

\section{CS Suppression}

Since the target trials during conditioning could have been differentially affected by different shock intensities of the preceding trials, only the extinction data were subjected to analyses regarding conditioned suppression. For nine days of extinction, means of the number of licks during 5-s CS presentations and those during 5-s periods immediately preceding the CS were calculated for target trials. For Group C, they were separately calculated for the $\mathrm{CS}$ associated with the weak shock $\left(\mathrm{CS}_{\mathrm{w}}\right)$ and for that associated with the strong shock $\left(\mathrm{CS}_{\mathrm{S}}\right)$. The results of Group $\mathrm{C}$ were depicted in the left half of the upper panel of Fugure 3. For Group UC, the bars labeled $C S_{w^{\prime}}$ and $C S_{s}$. represent mean number of licks calculated for the target trials corresponding in trial location to the $\mathrm{CS}_{\mathrm{W}}$ and 
$\mathrm{CS}_{\mathrm{s}}$ of Group $\mathrm{C}$, respectively.

The results shown on the upper panel of Figure 3 may be summarized as follows: (a) The pre-CS licking rate is higher for Group C than for Group LC. regardless of the types of trial or of CS. (b) There is clear evidence of conditioned suppression to CSs in both groups. (c) Suppression is greater in reaction to $\mathrm{CS}_{\mathrm{s}}$ than to $\mathrm{CS}_{\mathrm{w}}$ in Group $\mathrm{C}$, but there is no difference in suppresion as a result of $C S_{\mathrm{s}}$ or $\mathrm{CS}_{\mathrm{w}}$ in Group UC. The results of Groups $(\mathrm{G}) \times \mathrm{CS}(\mathrm{C}) \times \operatorname{Periods}(\mathrm{P})$ ANOVA revealed that all the main effects were significant $(\mathrm{G}: F(1,26)=21.87, p<.001: \mathrm{C}$ : $F(1,26)=8.08, p<.01: \mathrm{P}: F(1,26)=86.73$. $p<.001$ ). All the first-order interaction effects were also significant $(\mathrm{G} \times \mathrm{C}: F(1$, $26)=18.68, p<.001: \mathrm{G} \times \mathrm{P}: F(1,26)=5.30$, $p<.05 ; \mathrm{C} \times \mathrm{P}: F(1.26)=12.46 . p<.001$, respectively). The second-order interaction effect

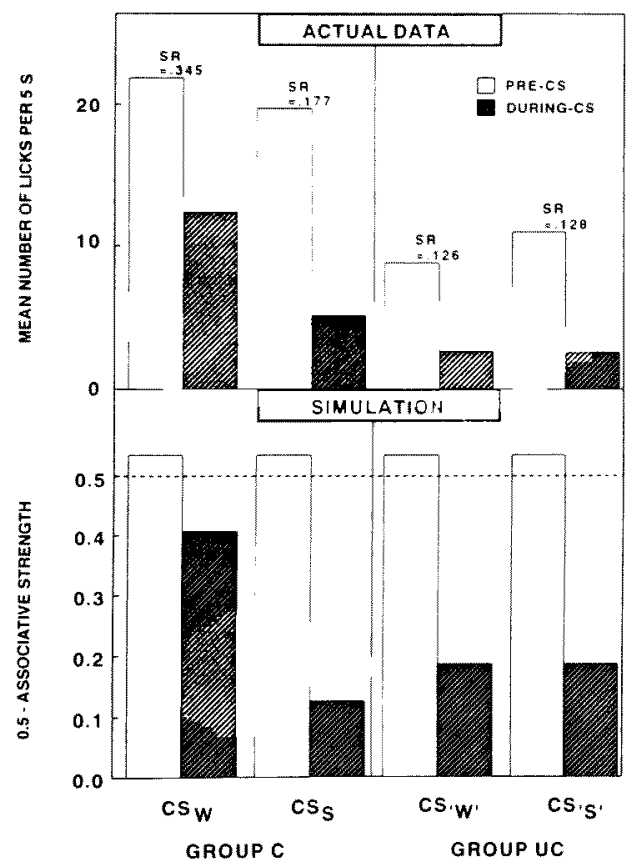

Figure 3. Means of pre-and during CS number of licks per $5 \mathrm{~s}$ for nine days of extinction for target trials with different kinds of CSs (upper panel) and corresponding simulation results (lower panel). For more details, see text. did not prove to be significant $(F(1$, $26)=1.88$ ). The results of this statistical analysis generally confirm what has been summarized above.

The suppression ratios (SRs) corresponding to the upper panel of Figure 3 were calculated using the formula of $B /(A+B)$, where $B$ represents the number of licks during the $C S$ presentation and $A$ the number of licks during 5-s period immediately before the onset of the CS. For each subject, a single SR was calculated combining all $A s$ and $B$ s over nine days, and the mean was calculated for each group and for each CS type. The SRs thus calculated were $.345, .177, .126$, and .128 for $\mathrm{CS}_{w}, \mathrm{CS}_{\mathrm{s}}, \mathrm{CS} \mathrm{S}_{\mathrm{w}}$, and $\mathrm{CS}$, , respectively. These SRs are shown on the upper panel of Figure 3. A Groups $(\mathrm{G}) \times \operatorname{CSs}(\mathrm{C})$ ANOVA revealed that all the main effects and the interaction effect were significant ( $G$ : $F(1,26)=15.84 . p<.001 ; \mathrm{C}: F(1.26)=7.79$, $p<.01 ; \mathrm{G} \times \mathrm{C}: F(1,26)=8.14, p<.01$, respec tively).

The results of the computer simulation for conditioned suppression are shown on the lower panel of Figure 3.

Results of Computer Simulation

On the lower panels of Figures 2 and 3 are presented the results of a computer simulation based on the Rescorla-Wagner model in such a way that the simulated data are easily compared with the actual data (upper panels of Figures 2 and 3). In order to run a computer simulation, the entire session of $300 \mathrm{~s}$ was first regarded as consisting of 60 segments of 5-s duration each, and it was assumed that one of seven types of 'stimulus presentations' shown in the Appendix (e.g., $A-E S_{w}, B-E S_{s}$, etc.) occupied any particular segment. In light of a successful computer simulation conducted in a previous experiment in exactly the same licking conditioned suppression situation (Fujii, 1988), the following values were used here. First, the salience of $\mathrm{CS}_{A}, \mathrm{CS}_{\mathrm{B}}$, and $\mathrm{CS}_{\mathrm{CONTEXT}}$ were set 
at .4. . and .1, respectively. The asymptotes of conditioning supported by the weak and no shock were 2 and 0 , respectively, throughout the conditioning phase. The asymptotes of the stronger shocks of $140 \mathrm{~V}$ used for the first half of conditioning and of $180 \mathrm{~V}$ used for the latter half of conditioning were 4 and .6 , respectively. The learning rate parameters for the weak and no shock were kept at .2 and .1, respectively, throughout conditioning. The learning rate parameters for the stronger shocks were 4 and .6 for $140 \mathrm{~V}$ and $180 \mathrm{~V}$, respectively. During the extinction phase, the asymptote supported by no shock and learning rate parameter for nonreinforcement were 0 and 1 , respectively. Other parameters were assigned the same values as those listed in the conditioning phase. In running the simulation, actual stimulus sequences used in the present exper-

In general, the Rescorla-Wagner model describes the Pavlovian conditioning process on a trial-by-trial basis with the equation of $\Delta V_{s}=\alpha_{1} \beta_{1}\left(\lambda_{1}-\dot{V}\right)$ (Rescorla. 1972: Rescorla \& Wagner, 1972; Wagner \& Rescorla, 1972). The change in the associative strength of a certain stimulus $A\left(\Delta V_{A}\right)$ is detined by the difference between the asymptotic level of conditioning supported by an unconditioned stimulus US $\left(\lambda_{1}\right)$ and the total associative strength of all the stim. uli on that trial $\left(\dot{V}=V_{i}+V_{i}\right)$. The learning rate parameters for the stimulus $A$ and $U S_{,}$are $\alpha_{4}$ and $\beta$, respectively (Fujii, 1988).

In the present experiment, the changes in associative strengths of the two stimuli, $A$ and $B$, and Contexi $1 \mathrm{C}$ ) are described as follows:

Stimulus $\mathrm{A}: \Delta \mathrm{V}_{\mathrm{A}}=\alpha_{4} \beta_{1}\left(\lambda_{1}-\dot{\mathrm{V}}\left(=\mathrm{V}_{\mathrm{A}}+\mathrm{V}_{\mathrm{C}}\right)\right)$

Stimulus $\mathrm{B}: \mathrm{J} \mathrm{V}_{\mathrm{B}}=\alpha_{\mathrm{B}} \beta\left(\lambda-\dot{\mathrm{V}}\left(=\mathrm{V}_{\mathrm{B}}+\mathrm{V}_{\mathrm{C}}\right)\right)$

Stimulus $C: \Delta \mathrm{V}_{c}=\alpha \beta_{\mathrm{ss}}\left(0-\mathrm{V}_{\mathrm{c}}\right)$

The subseript "NS" stands for "No Shock." The asymptote of conditioning supported by nonreinforcement is assumed to be zero (take a closer look at the third equation). It is commonly hypothesized that linear relationships exist between $V_{c}$ and baseline response, and also between associative strengths of $\mathrm{A}$ and $\mathrm{B}$ and CS-suppression to respective stimuli. iment were replicated.

In looking at the lower panel of Figure 2, it is important to note that the values along the ordinate axis are in reverse order, with negative values at the top. This system makes for convenient comparison of the simulated results with the actual data shown on the upper panel. Thus, as the associative strength $\left(\mathrm{V}_{\text {Con } \mathrm{FiT}}\right)$ increases, the ordinate values decrease. It is clear from these simulated results that the ordinate values of $V_{\text {CoNTEXT }}$ of Group UC (filled circles) are consistently greater than those of Group $C$ (unfilled circles) in the conditioning phase, although the difference is small. It is also clear that the values of $\mathrm{V}_{\text {contr:x }}$ for both groups decrease rapidly across days, and that there is virtually no difference between the two groups on Day 18 of conditioning. Notice that the values on Day 18 are each less than .02 , indicating that the associative strengths of the context are negligibly small in both groups. The large difference observed between groups, with respect to baseline number of licks during conditioning and extinction disaccords with the simulation results. Furthermore, the simulation did not predict the divergent licking behavior depicted on the upper panel of Figure 2 (compare upper and lower panels of this figure).

On the lower panel of Figure 3, the simulated values of the associative strengths as subtracted from an arbitrary value of .50 are shown for nine days of extinction. This transformation was performed for the convenience of easy comparison of the actual data with the simulated results. Four white bars on the lower panel of this figure, high and not differing in height, suggest that no and not differing contextual fear $\left(\mathrm{V}_{\text {ContExT }}\right)$ was found in all of the four conditions. It is evident, by comparing the upper and lower panels of Figure 3, that the height of white bars for Group UC marks the point of greatest discrepancy between the actual and simulated 
results. In other words, the mean number of licks in a 5-s period just prior to the CS-onset which was then followed by an uncorrelated shock is far less than what the computerized outcomes might have predicted.

\section{Discussion}

As shown on the upper panel of Figure 3 . conditioned suppression to the CSs was evident in both Groups C and UC. Moreover. differential conditioned suppression was observed only in Group C; the suppression to the CS paired with the strong shock $\left(\mathrm{CS}_{\mathrm{s}}\right)$ was greater than suppression observed when the CS was paired with the weak shock $\left(\mathrm{CS}_{w}\right)$. This pattern of shock intensity discrimination shown in the left half of the upper panel of Figure 3 accords with the results of computer simulation based on the Rescorla-Wagner model as may be seen on the lower left panel of Figure 3. The outcome also confirms what was found years ago in our laboratory under the same licking suppression circumstances (Yoshida, Kai, \& Imada, 1969, Experiment 2). In Group UC, for which the CS and the shock intensity were uncorrelated, there was no reason to expect suppression to differ between $\mathrm{CS}_{\mathrm{W}}$ and $\mathrm{CS}_{\mathrm{s}}$ trials. Our experimental data confirmed this prediction. This outcome is demonstrated by the approximately equal SRs to $\mathrm{CS}_{\mathrm{w}^{\prime}}$ and $\mathrm{CS}$. However, an initial assumption that these values would fall between Group C's high SR for $\mathrm{CS}_{S}$ and low $\mathrm{SR}$ for $\mathrm{CS}_{\mathrm{w}}$ was not confirmed (Note the relative heights of the hatched bars in Figure 3). These results regarding conditioned suppression clearly indicate that in Group $\mathrm{C}$ the information about shock intensity was well assimilated by rats of this group.

With regard to the baseline suppression, the present experiment clearly demonstrated that baseline licking behavior was suppressed more in Group UC than in Group C. This indication of stronger contextual fear in Group UC, combined with the evident overall stronger fear of CSs in this group is consistent with the prior finding that rats preferred the situation where information about the shock intensity was present to the situation where such information was absent (Marline et al., 1979). The higher observed levels of contextual fear and total CS-fear in Group UC than in Group C are consistent, at least in the direction of the results, with what was predicted by the Rescorla-Wagner model (see Figures 2 and 3). However, the present results involve the following discrepancies with the predicted outcomes: (a) The difference in contextual fear between Groups $C$ and $\mathrm{UC}$, as assessed by baseline number of licks, is far greater than that predicted by the Rescorla-Wagner model. The discrepancy is apparent in the differences between the upper and lower panels of Figure 2. (b) The diverging curves of Groups $\mathrm{C}$ and UC during conditioning is not what is predicted by the Rescorla-Wagner model (compare upper and lower panels of Figure 2). (c) The SRs for $\mathrm{CS}_{\mathrm{w}}$ and $\mathrm{CS}_{\mathrm{S}}$ of Group UC do not reflect values between the high and low SRs for $\mathrm{CS}_{\mathrm{S}}$ and $\mathrm{CS}_{w}$ of Group $\mathrm{C}$, a finding inconsistent with what is predicted by the RescorlaWagner model (see the lower panel of Figure 3).

One may argue that the poor fit of simulations with our observed data is due in part to inappropriate choices of parameters for the simulation. The contextual fear even in Group $\mathrm{C}$ was not extinguished by the end of conditioning as suggested by moderately suppressed baseline licking. Nevertheless, the parameters chosen for simulations were such that the $V_{\text {Context }}$ did end up with near zero values on the last day of conditioning. However, it should be remembered that, of 60 5-s segments composing a session, 56 segments were extinction 'trials' for the context. It is therefore virtually impossible to choose parameters in such a way that the 
$V_{\text {context }}$ ended up with values well below zero, unless very unlikely assumptions were made. Apart from this problematic nuance, large and diverging differences between Groups $\mathrm{C}$ and UC depicted in the curves drawn on the upper panel of Figure 2 are not what appear on the lower panel of the same figure. There are some other discrepancies between the obtained data and the simulation results as seen in Figures 2 and 3, but any attempt to choose parameters for the sake of a better 'fit' in one aspect of the results yielded only worse discrepancies in other aspects. It should be concluded, therefore, that, at least within the range of parameters chosen in the present study, the results of the present experiment cannot be adequately explained by the contextual fear hypothesis (Fanselow, 1980) based on the Rescorla-Wagner model of classical conditioning (Rescorla, 1972; Rescorla \& Wagner, 1972; Wagner \& Rescorla, 1972).

Imada and Nageishi (1982) reviewed rat experiments using aversive stimuli in which various elements of uncertainty were involved. They classified the experiments into nine cases according to the nature of uncertainty and discussed them with reference to the following five hypotheses: the safety signal hypothesis, the preparatory response hypothesis, the information hypothesis, the time allocation hypothesis and the contextual fear hypothesis. Imada and Nageishi (1982) then concluded that: "The results of experiments using the correlated/uncorrelated paradigm cannot be fully understood by any existing hypotheses ..." (p. 586). The present experiment, which applies to Case 5 of the above classification, added another instance which cannot be fully explained in terms of the hypotheses stated above. A theory is awaited that could explain experimental findings using correlated/uncorrelated paradigm as used in the present study without having recourse to "such an ambiguous term as uncertainty" (Imada \& Nageishi, 1982, p. 586).

\section{References}

D'Amato,M. R., \& Safarjan, W. R. 1979 Preference for information about shock duration in rats. Animal Learning \& Behavior, 7, 89-94.

Fanselow,M. S. 1980 Signaled shock-free periods and preference for signaled shock. Journal of Experimental Psychology: Animal Behavior Processes, 6, 65-80.

Fujii, M. 1988 Pavlovian conditioned inhibition in a licking conditioned suppression situation with rats: An examination of the Rescorla-Wagner model. Japanese Journal of Psychonomic Science, 6, 95-100.

Imada, H., \& Nageishi, Y. 1982 The concept of uncertainty in animal experiments using aversive stimulation. Psychological Bulletin, 91, 573-588.

Imada, H., Shuku, H., \& Moriya, M. 1983 Can a rat count? Animal Learning \& Behavior, 11, 396400

Marlin, N.A., Sullivan, J. M., Berk, A. M., \& Miller, R. R. 1979 Preference for information about intensity of signaled tailshock. Learning and Motivation. 10, 85-97.

Nageishi,Y., \& lmada, H. 1974 Suppression of licking behavior in rats as a function of predictability of shock and probability of conditioned-stimulusshock pairings. Journal of Comparative and Physiological Psychology, 87, 1165-1173.

Rescorla, R, A.1972 Informational variables in Pavlovian conditioning. In G. H. Bower (Ed.), The psychology of learning and motivation. Vol.6. New York: Academic Press. Pp. 1-46.

Rescorla, R. A., \& Wagner, A. R. 1972 A theory of Pavlovian conditioning: Variation in the effectiveness of reinforcement and nonreinforcement. In A. Black \& W. F. Prokasy (Eds.), Classical conditioning II. New York: Appleton-CenturyCrofts. Pp. 64-99

Wagner, A. R., \& Rescorla, R. A. 1972 Inhibition in Pavlovian conditioning: Application of a theory. In R. A. Boakes \& M. S. Halliday ( Eds.), Inhibition and learning. New York: Academic Press. Pp. 301-336.

Yoshida, T., Kai, M., \& Imada, H. 1969 A methodological study of CER in rats with 'licking' as the criterion response. Japanese Psychological Research, 11, 66-75.

(Received Nov. 11, 1992; accepted Jan. 8, 1994) 


\section{Appendix}

Seven Types of Stimulus Presentations Given in any Particular Segment of the Entire Session

\begin{tabular}{|c|c|}
\hline Group C & Group UC \\
\hline \multirow[t]{2}{*}{$\begin{array}{l}\mathrm{A}-\mathrm{ES}_{\mathrm{u}} \\
\quad \mathrm{IV}=\alpha_{\mathrm{A}} \beta_{\mathrm{u}}\left(\lambda_{\mathrm{H}}-\dot{\mathrm{V}}\right) \\
\mathrm{IV}=\alpha_{\mathrm{A}} \beta_{\mathrm{u}}\left(\lambda_{\mathrm{u}}-\dot{\mathrm{V}}\right)\end{array}$} & $\begin{array}{l}\mathrm{A}-\mathrm{ES} \\
\Delta \mathrm{V}_{\mathrm{H}}=\alpha_{\mathrm{A}} \beta_{\mathrm{W}}\left(\lambda_{\mathrm{H}}-\dot{\mathrm{V}}\right) \\
\Delta \mathrm{V}_{\mathrm{C}}=\alpha_{1} \beta_{\mathrm{H}}\left(\lambda_{\mathrm{W}}-\dot{\mathrm{V}}\right)\end{array}$ \\
\hline & $\begin{array}{l}\mathrm{A}-\mathrm{ES} \\
\begin{aligned} \Delta \mathrm{V}_{\lambda} & =\alpha_{\hat{A}} \beta_{1}\left(\lambda_{-}-\dot{\mathrm{V}}\right) \\
\Delta \mathrm{V}_{\mathrm{c}} & =\alpha_{c} \beta_{\mathrm{s}}\left(\lambda_{\mathrm{C}}-\dot{\mathrm{V}}\right)\end{aligned}\end{array}$ \\
\hline \multirow[t]{2}{*}{$\begin{array}{l}\mathrm{B}-\mathrm{ES} \\
\Delta \mathrm{V}_{\mathrm{B}}=\alpha_{\mathrm{B}} \beta_{\mathrm{s}}\left(\lambda_{\mathrm{s}}-\dot{\mathrm{V}}\right) \\
\Delta \mathrm{V}_{\mathrm{S}}=\alpha_{\mathrm{S}} \beta_{\mathrm{s}}\left(\lambda_{\mathrm{s}}-\dot{\mathrm{V}}\right)\end{array}$} & $\begin{array}{l}\mathrm{B}-\mathrm{ES}_{\mathrm{S}} \\
\Delta \mathrm{V}_{\mathrm{B}}=\alpha_{\mathrm{B}} \beta_{\mathrm{s}}\left(\lambda_{\mathrm{S}}-\dot{\mathrm{V}}\right) \\
\Delta \mathrm{V}_{\mathrm{c}}=\alpha_{1} \beta_{\mathrm{s}}\left(\lambda_{-}-\dot{\mathrm{V}}\right)\end{array}$ \\
\hline & $\begin{array}{l}\mathrm{B}-\mathrm{ES}_{\mathrm{w}} \\
\Delta \mathrm{V}_{\mathrm{B}}=\alpha_{\mathrm{B}} \beta_{\mathrm{w}}\left(\lambda_{\mathrm{w}}-\dot{\mathrm{V}}\right) \\
\Delta \mathrm{V}_{1}=\alpha_{1} \beta_{w}\left(\lambda_{w}-\dot{\mathrm{V}}\right)\end{array}$ \\
\hline
\end{tabular}

CONTEXT

$\Delta \mathrm{V}_{\mathrm{c}}=\alpha, \beta_{\mathrm{s}}\left(0-\mathrm{V}_{\mathrm{c}}\right)$

Notes:

1. Abbreviations:

$\Delta \mathrm{V}$ : Amount of change in associative strength in a 5 -s segment

$\dot{V}$ : Total associative strength of all the stimuli including contextual stimuli

$\lambda$ : Asymptote of conditioning supported by a US

$\alpha \quad$ : Leaming rate parameter of a CS

$\beta$ : Learning rate parameter of a US

2. Subscriptions $\mathrm{A}, \mathrm{B}$, and $\mathrm{C}$ designate stimuli $A$, B, and C (Context), respectively. Subscriptions $\mathrm{S}$ and $\mathrm{W}$ signify stronger and weaker shocks, respectively.

3. Zero in parentheses for context indicates the asymptote of nonreinforcement. 